\title{
MS35-P25 | Revealing Mechanical Plastic Bending in Coordination Polymer
}

\section{CRYstals}

BHATTACHARYA, BISWAJIT (BAM Federal Institute for Materials Research and Testing, Berlin, GER); Michalchuk, Adam A. L. (BAM Federal Institute for Materials Research and Testing, Berlin, GER); Emmerling, Franziska (BAM Federal Institute for Materials Research and Testing, Berlin, GER)

Crystalline molecular materials with mechanical flexibility are promising for technological development. While a growing number of mechanically flexible crystalline molecular materials are being reported, ${ }^{1}$ they remain scarce. At present, most discoveries are serendipitous, as limited design strategies are currently known. Amongst these strategies Desiraju et. al. suggested that elastic materials must contain herringbone structures. ${ }^{2}$ For plastic crystals, the so-called 'shape-synthon' strategy has been developed, in which weak non-covalent interactions are introduced into structures to facilitate mobility of molecules. ${ }^{3}$ This includes formation of slip planes. Generally, these models have performed very well at predicting and rationalizing the mechanical properties of new materials. Recently, however, a family of one-dimensional covalent networks (coordination polymers; CPS) has been described, which show mechanical elasticity. With drastically different structural chemistry, these systems do not seem to adhere to the currently established rules. Herein, we present the first such system: a plastically bendable crystal of a $1 \mathrm{D} \mathrm{CP},\left[\mathrm{Zn}(\mathrm{m}-\mathrm{Cl})_{2}\left(\mathbf{3}, \mathbf{5}-\mathrm{Cl}_{2} \mathrm{Py}\right)_{2}\right]_{n}$ (where 3,5-Cl $\mathrm{Py}=3,5$-dichloro pyridine). This $\mathrm{CP}$ crystallizes in a tetragonal, and can therefore be bent over two major faces to acute angles without fracturing. We conducted bending and indentation experiments to quantify the mechanical properties of the CP crystal. This was complimented by Vibrational (Raman and Terahertz) spectroscopy and theoretical calculations for deeper understanding of molecular level structural deformation.

[1] Acc. Chem. Res., 2018, 51, 2957-2967.

[2] Angew. Chem. Int. Ed., 2015, 54, 2674-2678.

[3] J. Am. Chem. Soc., 2016, 138, 13561-13567.

[4] Angew. Chem., 2018, 130, 15017-15021. 